\title{
Cost-Benefit Analysis of Mood Uplifting Paintings in Hospitals
}

\author{
Simin Mozayeni \\ State University of New York at New Paltz \\ Maryalice Citera \\ State University of New York at New Paltz \\ Parisa Amirmostofian \\ Ikon Institute of Australia
}

The Net Present Value of Benefits (NPVB) of installing mood uplifting paintings on hospital stay lengths were projected using a Cost-Benefits analysis. Net benefits were estimated from the "effect size" of mood uplift from Abstract Romanticism paintings and the average cost of hospital stay at \$2,000/day. We used a nominal Social Discount Rate of $4 \%$ and a period of ten years. The analysis was conducted for a sample of hospitals and states. The results showed that installation of Abstract Romanticism paintings would have net benefits and this enhancement to the patient environment would likely result in substantial healthcare savings.

Keywords: hospital art, cost-benefit analysis, healthcare cost, aesthetics, abstract romanticism, kamran khavarani

\section{INTRODUCTION}

The primary purpose of this research was to find an innovative and progressive way to reduce the cost of U.S. hospital care. Our research fills a void in both Aesthetics and Health Economic literatures. Hospital stay costs have been on a rising trajectory and are projected to rise about $6 \%$ per year (US Bureau of Labor Statistics). We examined whether a modest change to patient environment could result in an overall cost reduction for healthcare. To that end, we used the Cost-Benefit Model to evaluate the cost and benefits of installing artwork that would lift the mood of patients. This model is used by the Federal Government, the World Bank and private firms to evaluate the financial merit of their investment projects and for ranking alternatives (when applicable). The Abstract Romanticism paintings of Kamran Khavarani became our focus because the late Professor Albert Boime (2008b), perhaps the foremost Social Art Historian of our time, wrote that Khavarani's work “... resurrects the possibility that art can change the world by reaching out to the heart and imagination of the spectators." In addition, Mozayeni and her colleagues (Amirmostofian \& Mozayeni, 2016; Mozayeni \& Amirmostofian, 2016; Mozayeni, Heiner \& Amirmostofian, 2017) found that viewing Khavarani's Abstract Romanticism paintings resulted in significant improvements in reported mood compared to viewing paintings of other artists. There is a growing awareness that visual elements of the patients' environment (like artwork on the wall, a window 
in the room) facilitate the healing process and are associated with reductions in hospital stay length (Eisen, Ulrich, Shepley, Varni, \& Sherman, 2008; Hathorn \& Nanda, 2008; Lankston, Cusack, Fremantle, \& Isles, 2010; Sherman, Varni, Ulrich, \& Malcarne, 2005; Sternberg, 2009; Ulrich, 2006; Ulrich, 2013; Ulrich, Bogren, Gardiner, \& Lundin, 2018). Hathorn and Nanda (2008) argued that art should be used as a positive distraction - to divert patient attention from the stress of the hospital environment.

The literature shows that paintings do affect viewers' emotion in hospitals. Many hospital administrators are beginning to recognize that fact. Hathorn and Nanda (2008) reported that a 2003 national survey concluded that $73 \%$ of the 2,000 responding hospitals had permanent displays of visual arts. The art selections of hospitals matter. A case in point can be seen in Figure 1. This reproduction is installed in a major New York hospital that is a center for complicated surgeries, including heart surgeries and liver transplants. The figure depicts an operating room scene with surgical team, an array of surgical tools, and even blood. Instead of promoting well-being, however, this display might trigger a fear reaction in patients about to undergo surgery.

FIGURE 1

OPERATING ROOM ARTWORK INSTALLED IN A MAJOR NY HOSPITAL

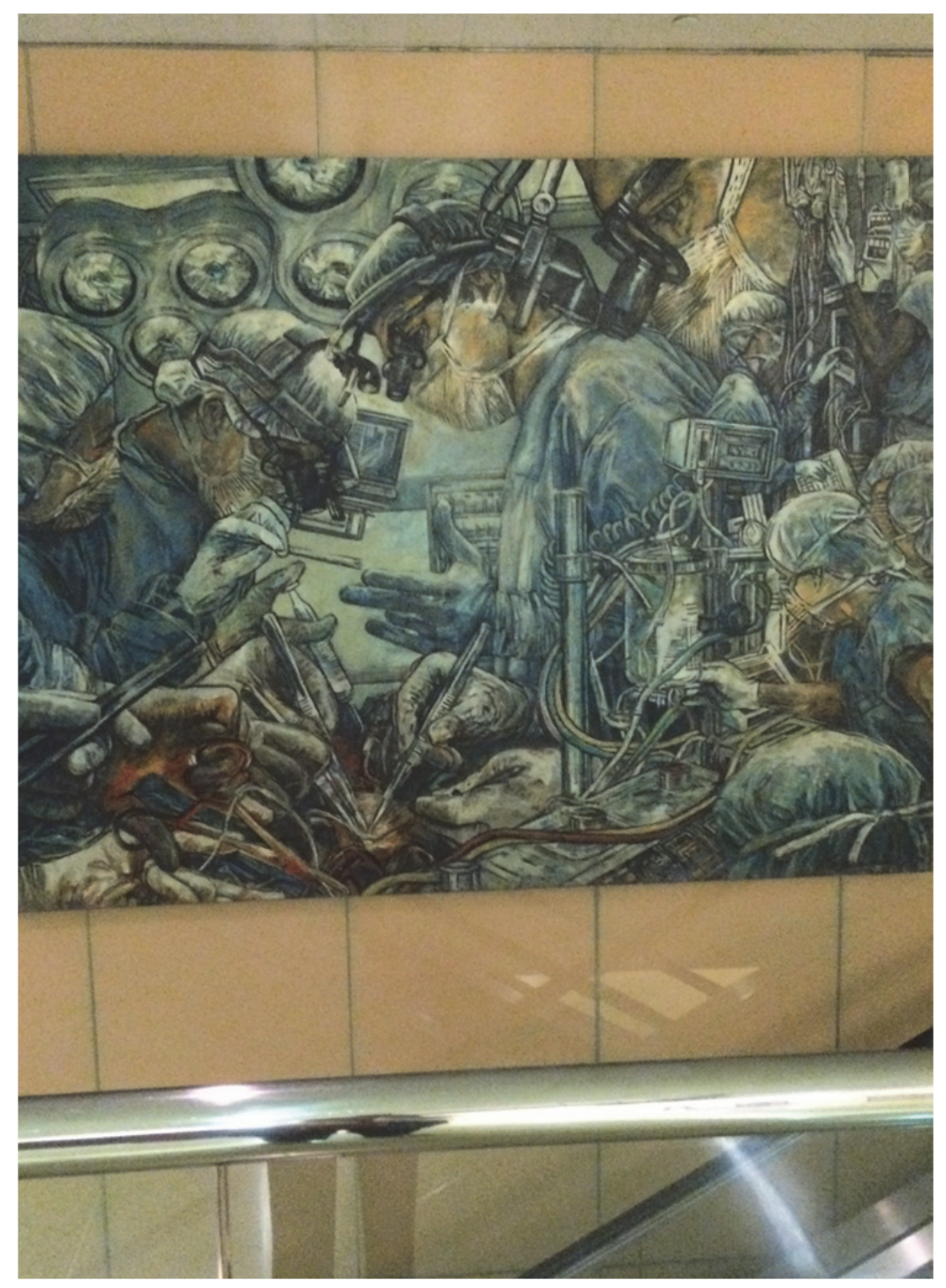


Hospitals have begun to recognize the therapeutic benefit of visual art. Hathorn and Nanda (2008) called for evidence-based analysis of the effects of art interventions on health outcomes. We offer an evidence-based approach that explores the Cost-Benefit outcomes of installing visual arts with a calming effect in hospitals.

We argue that there would be a benefit if hospitals displayed art that stimulates positive emotions. First, we review the literature that shows that viewing art can evoke strong emotions. We summarize research that shows reduced distress leads to improved health outcomes. We make the case that installing uplifting art in hospitals leads to positive benefits, including reduced hospital stays. Finally, we present a Cost-Benefit model to illustrate the potential cost savings that can be realized when hospitals use Abstract Romanticism paintings.

\section{Visual Art and Emotion}

There is a growing body of literature that shows that visual art can evoke strong emotions. Smith, Smith, and Tinio (2017) replicated earlier research showing that there was variability in the amount of time spent viewing artwork. Some people spent little time and sampled the artwork. Others consumed the artwork. Those who spent the most time savored the artwork.

Tinio and Gartus (2018) showed that people reported experiencing very similar emotional responses to the same pieces of art. These emotions were diverse and varied in intensity. They also showed that the emotions viewers reported corresponded to the emotions depicted in the art. When individuals spent more time viewing the art, they reported more intense and diverse emotions. The longer the viewing time, the more intense were feelings of involvement/interest and enjoyment/pleasure.

Pelowski et al. (2018) showed that viewers reported aesthetic experiences with pieces of visual art that were comparable. Viewers' reactions produced common emotional responses that were unique and distinct to the two pieces of art. Research also showed that artists' intentions about the emotions represented in an artwork can be felt and understood by viewers of the art (Pelowski, Specker, Gerger, Leder, \& Weingarden, 2018). Emotions felt by viewers were consistent with the emotions felt by artists creating the artwork, as well as the emotion the artist intended to evoke.

Kragel, Reddan, LaBar, and Wager (2019) reported that emotion schemas were embedded in the visual processing system. They demonstrated that visual images could be represented by a complex combination of visual features (e.g., angle, field size, eccentricity) that are linked to emotion schemas. They also showed that the FMRI's of individuals viewing visual art (photographs or video clips) processed emotional content in the visual cortex. This processing occurred at the sensory level and means that emotions are processed quickly and decoded at the same time as other visual features of the artwork. Kawabata and Zeki (2004) reported that the perception of different categories of paintings are associated with distinct and specialized visual areas of the brain, that the orbito-frontal cortex is differentially engaged during the perception of beautiful and ugly stimuli, regardless of the category of painting, and that the perception of stimuli as beautiful or ugly mobilizes the motor cortex differentially.

\section{Reduced Distress Leads to Positive Health Outcomes}

Sternberg (2009) suggested that a soothing environment can accelerate hospitalized patients' healing and reduce their stays. She argued "beauty" can trigger healing, instill peace, and reduce stress. She reviewed research indicating that the health of the environment is closely linked to personal health. In her research, she reported that arts in a hospital environment can reduce the duration of hospitalization. Hathorn and Nanda (2008) in their study of patients at a Utah Hospital, concluded that patients' experience was affected by the environment and not just the care they received. They suggested that "The physical environment is not a mere backdrop for healthcare delivery - it is an integral part of the hospital experience." (Hathorn \& Nanda, 2008, p. 1).

Empirical evidence supported the idea that recovery was linked to less stress. In a review of the effects of psychological variables on surgical recovery, Mavros, et al. (2011) reported that perceived stress/anxiety was correlated with slower surgical recovery. For elderly men with diabetes, Baharlooei, Alavi \& Adelmehraban (2017) found stress predicted the length of hospital stay. Greater stress was 
associated with longer hospital stays. Similarly, Wisely (2013) found that reducing psychological distress of burn victims improved wound healing and reduced the number of days it took for wounds to heal.

In his study of hospital environments, Ulrich (1984) found that hospital patients with window views of trees spent significantly fewer days (7.96) in the hospital than those without a window view (8.70). Patients with a tree view relied on less potent analgesics (acetaminophen and aspirin) and took fewer strong narcotics than those with a wall view.

Lankston and associates (Lankston, Cusack, Fremantle \& Isles, 2010) investigated the effects of paintings in three new hospitals in Scotland: Scotland's Royal Infirmary of Edinburgh, the Stobhill Hospital, and the Victoria Infirmary in Glasgow. They reported that both patients and staff viewed art in hospitals positively. A qualitative evaluation of the Exeter Healthcare Arts Project found that the display of visual arts in that hospital was perceived by patients, staff, and visitors to have a positive effect on optimism. They reported that $43 \%$ of frontline clinical staff believed that the arts had a positive effect on healing and $24 \%$ believed that the arts improved clinical outcomes.

Miles (1994) reported the positive benefits of an art residency program that improved the delivery of care in a mental health hospital. An artist worked with hospital staff and residents to produce art installations. At the end of the year-long residency, the majority of staff reported that the program had a positive effect on the delivery of care and created a calmer, more pleasant environment. This study differs from our study in several key ways. First the art residency was primarily about creating art and engaging patients in the activity. Second, the results looked at the perceptions of staff, but did not focus on direct patient benefits. Third, the patients of the mental health hospital were long-term residents. The goal was to improve the quality of long-term care and not on reducing the stay of patients.

Kaplan (1995) outlined the attention restoration theory which suggests that art and natural environments can serve a restorative function. Sustained attention causes stress and fatigue. Nature and art can redirect attention providing the opportunity for reflection and restoration. Art that leads to recovery encompasses four characteristics. First, they involve fascination. The ability to attract and hold attention. Second, they shift focus away from mental activity that cause fatigue/stress. Third they have extent, that is they are rich, coherent, and engage the mind. Fourth, they are compatible with the person's inclination.

The Abstract Romanticism paintings of Kamran Khavarani fit these four characteristics. Figures 2 to 5 show samples of his paintings. Albert Boime (2008) discovered this genre of painting and labelled it Abstract Romanticism.

Mozayeni and her colleagues examined the increase in mood that resulted from viewing Abstract Romanticism paintings. Amirmostofian and Mozayeni (2016) reported that viewing Abstract Romanticism paintings had a meditative effect on viewers. Mozayeni and Amirmostofian (2016) showed that viewers of Abstract Romanticism paintings, irrespective of their gender and age and their initial state of mood, reported an increase in positive mood. Mozayeni, et al. (2017), conducted a pattern analysis of mood reports of individuals who visited three galleries, one of which was the Abstract Romanticism gallery (Khavarani's Gallery). Before and after moods were reported by viewers for each gallery they visited. Patterns for combinations of order, gender and age were examined. The plots for the time series of individual scores showed that when participants visited Khavarani's gallery, they reported a significant increase in their mood. They also showed that the uplifting effect of Abstract Romanticism paintings lasted after viewers left the gallery. This was not true after visiting the other galleries. In addition, there was no discernible effect of order, gender, or age on mood scores. 
FIGURE 2

ABSTRACT ROMANTICISM PAINTING: 043L13WW_Freedom

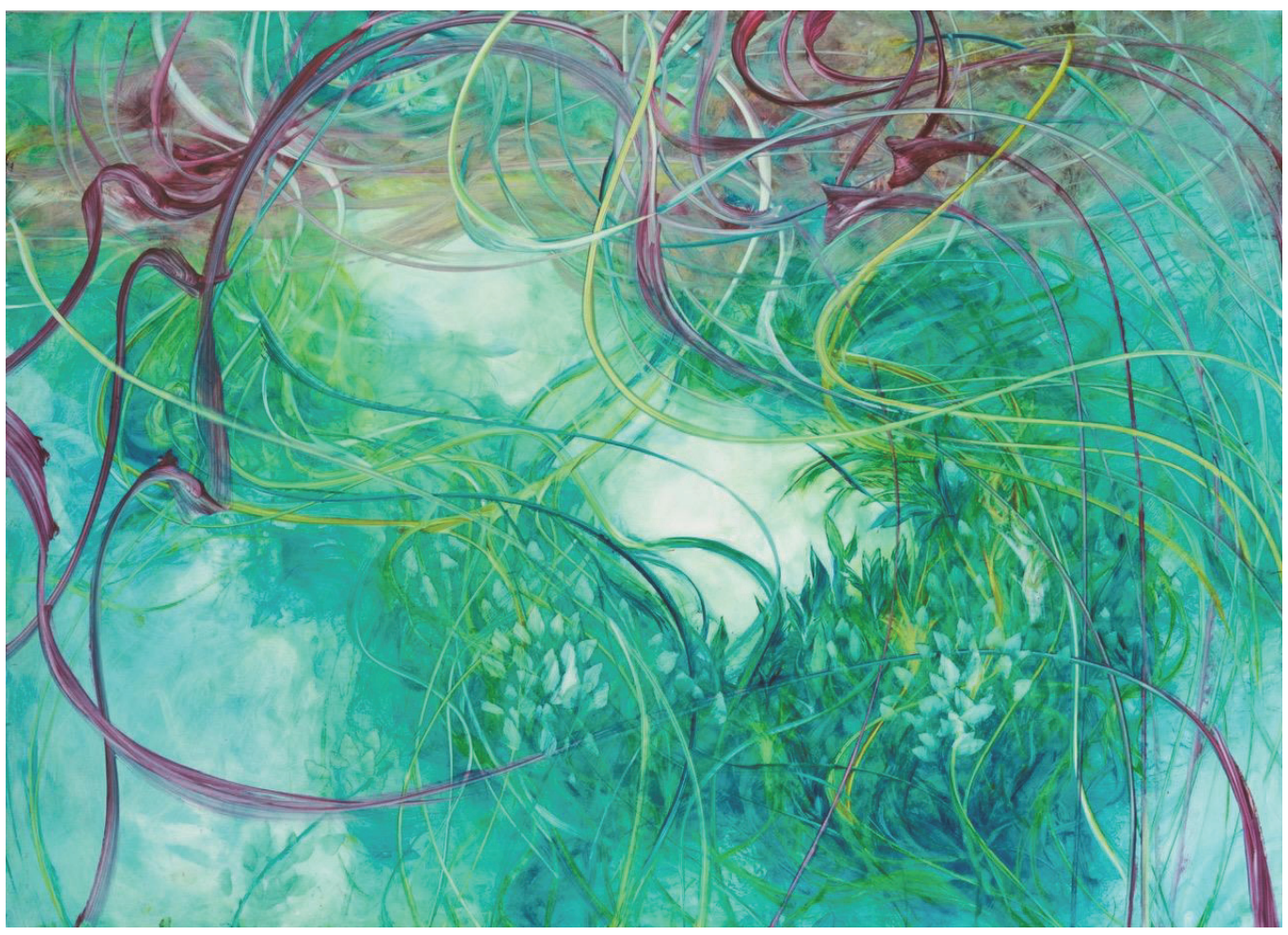

FIGURE 3

ABSTRACT ROMANTICISM PAINTING: 018L13WW_Tree of Life

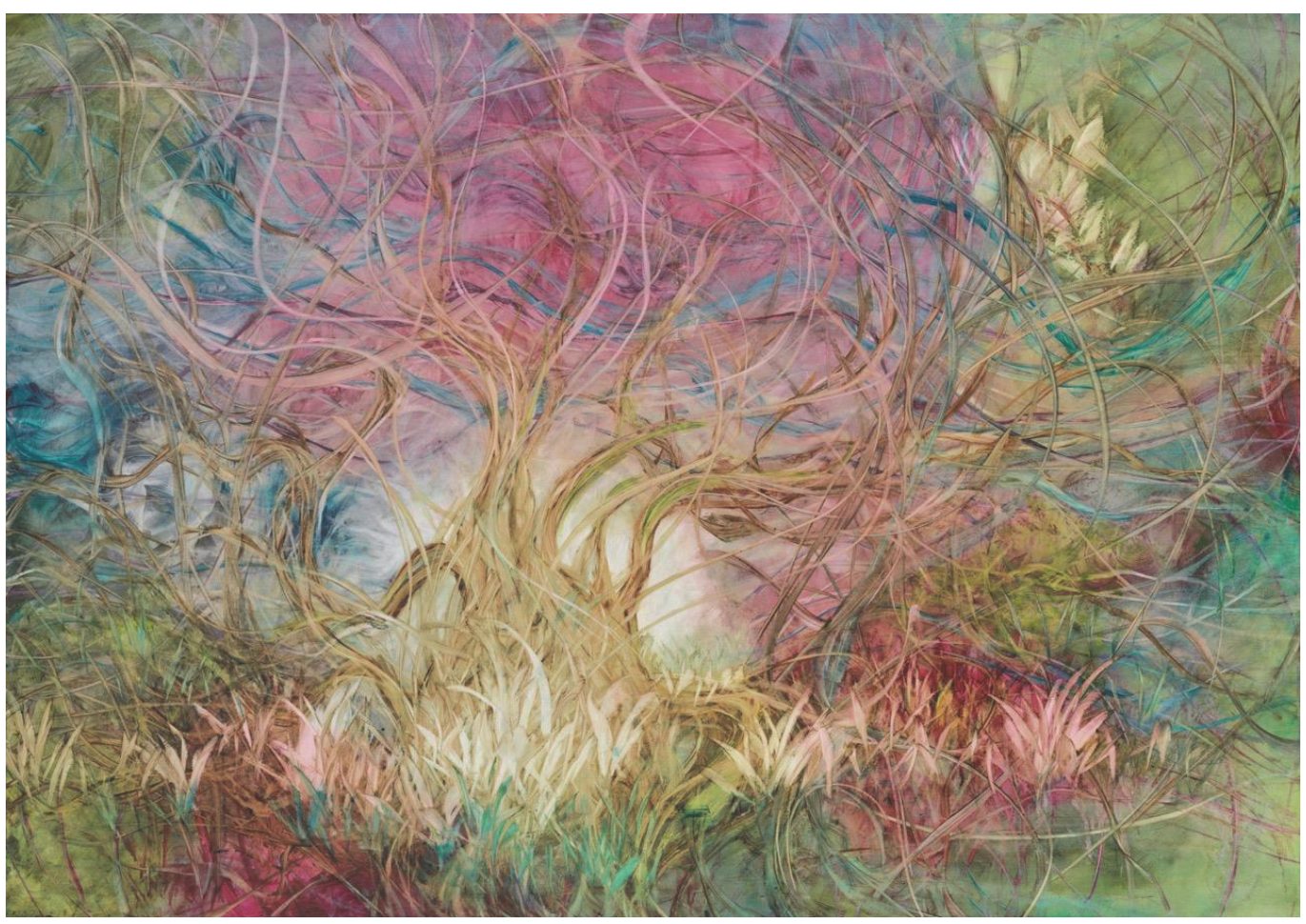


FIGURE 4

ABSTRACT ROMANTICISM PAINTING: 004L13WW_Unveiling

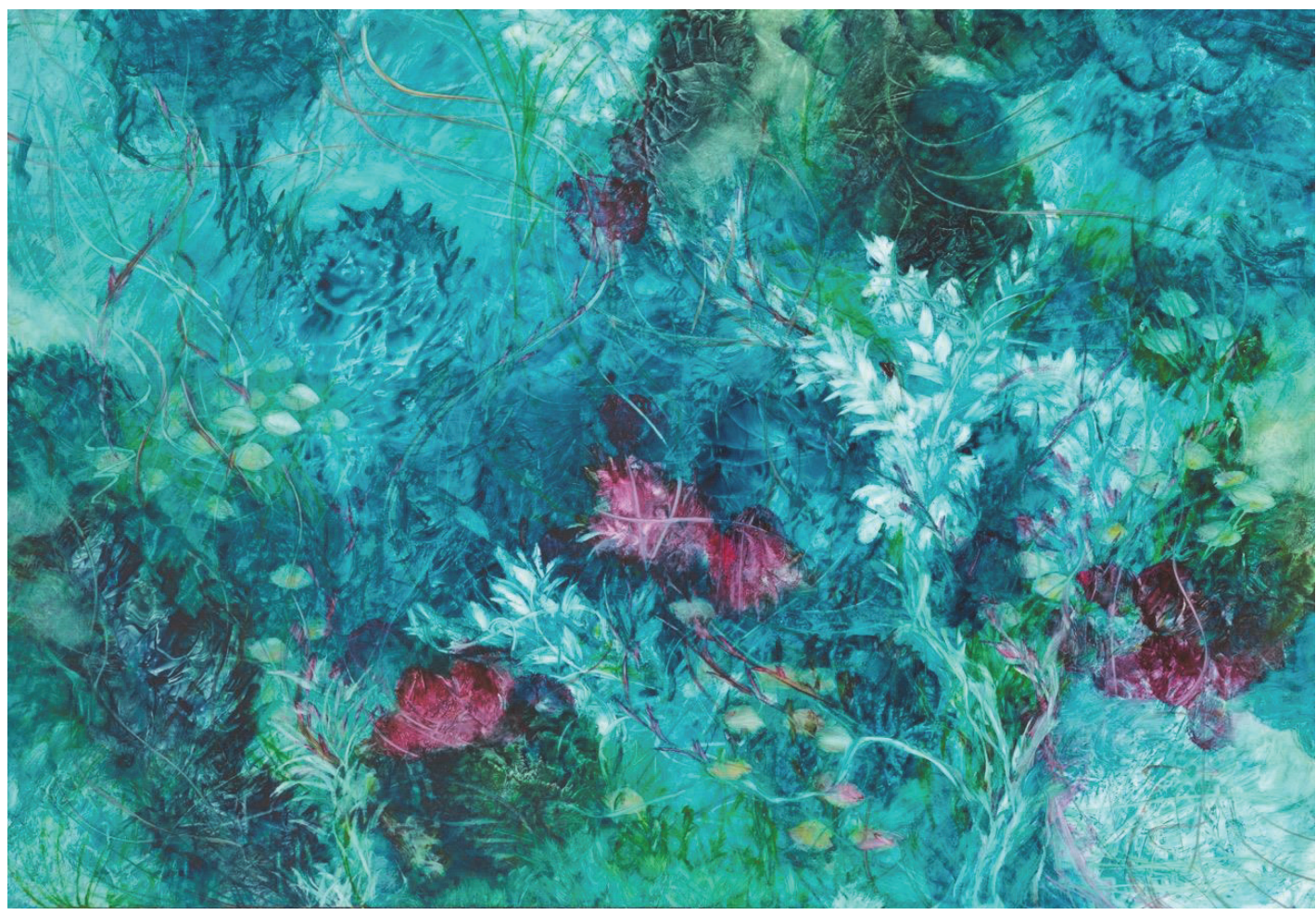

FIGURE 5

ABSTRACT ROMANATICISM PAINTING: 007L13WW_The Beginning

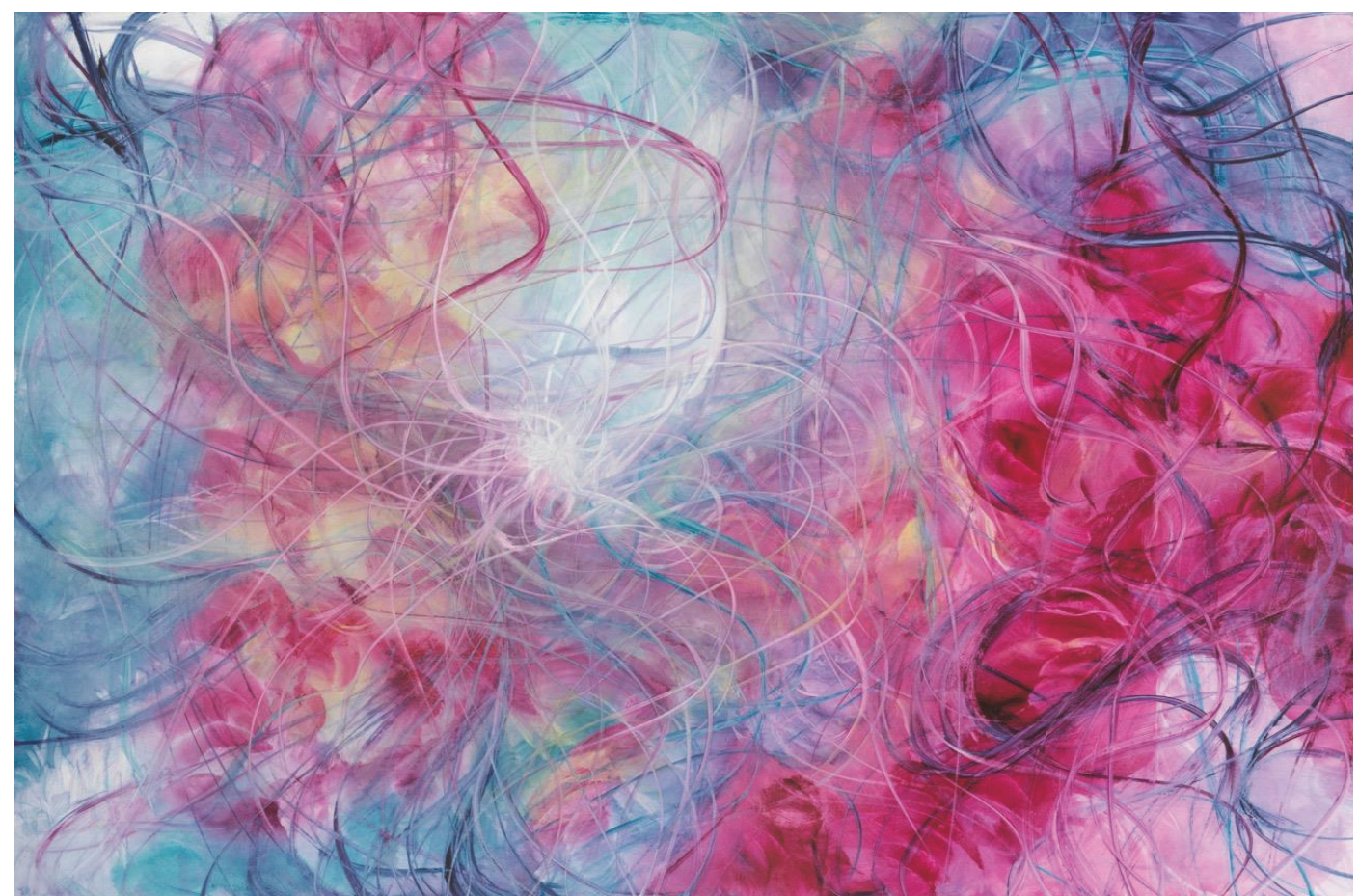

14 Journal of Organizational Psychology Vol. 20(1) 2020 
Based on previous research examining the uplifting power of the Abstract Romanticism (AR) genre of painting (Amirmostofian \& Mozayeni, 2016; Mozayeni \& Amirmostofian, 2016; Mozayeni, et al., 2017), we considered their use in hospitals. In the present study, we conducted a Cost-Benefit Analysis to predict the potential benefits of using the Abstract Romanticism genre of painting to reduce the length of hospital stays and thus associated costs. First, we examined three major hospitals in the U.S. and estimated what their cost savings would be if an Abstract Romanticism painting was installed in each patient room. Then we extended this to the three states with the most hospital beds and the three with the fewest hospital beds.

\section{METHODS}

A Cost-Benefit Model (Hyman, 2010) was applied to determine the Net Present Value of Benefits for the proposed project. The following were considered when developing our methodology and variables of our model:

a. The Cost-Benefit Model is routinely used by the Federal Government since the Reagan Administration and by the World Bank to evaluate the financial advantage of their projects and for ranking alternative projects, when pertinent. Private firms also use this model to evaluate their investment projects and prioritize their investment options. There are, however, a number of variables that need to be selected prudently. We detail our decision processes used to select these variables.

b. We take an evidence-based approach and derive our estimates from empirical data as elaborated below.

c. We are aware that other visual artworks (e.g., photographs of nature scenes) and genres of paintings may also have positive effects on patients' mood. Furthermore, we wish to acknowledge that we have NO information about the type of paintings currently installed in the sample entities in our study.

d. Our calculations of the cost of "paintings" is based on a quote from a dealer who carries Abstract Romanticism paintings. The quote is based on bulk purchases and with consideration for the nonprofit status of most hospitals. We have added $\$ 50$ to the quoted price of $\$ 250$ per piece for installation.

Salvage Value of the paintings, we excluded the installation cost and did not include any appreciation premium to their resell values.

e. We considered a time horizon of ten years, assuming hospitals may wish to use other artworks after 10 years. Hence, we calculated the sum of PV of future benefits and compared them with the initial cost of the paintings. For the salvage value of paintings, we chose to focus on initial cost of the paintings instead of the appreciated market value of the artwork or their nominal value after 10 years.

Our variables were: 1) the estimated installed cost of paintings; 2) projected savings from shorter hospital stays, and 3) the social discount rate. We took a very conservative approach to our estimations to avoid typical pitfalls in setting up the Cost-Benefit analysis. We only calculated the direct benefits of installing the artworks on patients, although it is likely that there are indirect benefits to staff and caregivers, as well. Hathorn \& Nanda (2008), observed that while patients and the public are the primary reasons to have arts programs, $55 \%$ of the programs they surveyed also focused on the reduction of stress and burnout in hospital staff. That said, we felt that we could not prudently quantify the dollar values for indirect benefits of installing artworks. Hence, we do not add a hypothetical figure to our equations of total benefits. There are, however, anticipated to be indirect benefits to the caregiver and employees which we cannot enumerate.

The PV of Costs and Benefits were calculated using Equations 1, 2 respectively. However, for Cost there is no PV calculation in our evaluations since costs occur one time only. 
$\mathrm{PVC}=\mathrm{C}_{1} /(1+\mathrm{r})^{1}+\mathrm{C}_{2} /(1+\mathrm{r})^{2}, \ldots \ldots . . \mathrm{C}_{\mathrm{n}} /(1+\mathrm{r})^{\mathrm{n}}$

$\mathrm{PVB}=\mathrm{B}_{1} /(1+\mathrm{r})^{1}+\mathrm{B}_{2} /(1+\mathrm{r})^{2}, \ldots \ldots . . \mathrm{B}_{\mathrm{n}} /(1+\mathrm{r})^{\mathrm{n}}$

In general, the present value of $\mathrm{X}$ dollars to be received in $\mathrm{n}$ years from now at simple interest rate $\mathrm{r}$ is obtained by solving the equation $\mathrm{X}=\mathrm{PV}(1+\mathrm{r})^{\mathrm{n}}$. Present value for benefits of $\mathrm{X}$ in $\mathrm{n}$ years is:

$\mathrm{PV}=\mathrm{X}_{1} /(1+\mathrm{r})^{1}+\mathrm{X}_{2} /(1+\mathrm{r})^{2}+\ldots \ldots \ldots \mathrm{X}_{\mathrm{n}} /(1+\mathrm{r})^{\mathrm{n}}$. Thus, Net Benefit, PV(B)-PV(C), was calculated based on Equation 3, where $\mathrm{S}$ denotes the Salvage Value of investment (when applicable).

$B_{1} /(1+r)^{1}+B_{2} /(1+r)^{2}, \ldots \ldots . . B_{n} /(1+r)^{n}-\left[C_{1} /(1+r)^{1}+C_{2} /(1+r)^{2}, \ldots \ldots . . C_{n} /(1+r)^{n}+S\right.$

\section{Cost Data}

The estimated installed costs of the paintings were based on data for the number of beds and the bulk reproduction cost of $\$ 300$ per installed painting. For each artwork, we assumed the bulk reproduction price would be 5\% of the market price based on the 2018-19 gallery price of $\$ 5,000$. For the quantities we project, the estimated purchase price would be $\$ 250$. Based on national average, we have added $\$ 50$ for installation cost. The number of paintings needed for each entity was calculated based on the number of hospital beds for that entity according to the American Hospital Directory for States. We considered one painting per patient room, assuming a standard semi-private room with two patients in a room who could easily share viewing one piece. We do not need to discount this cost for future values, since it is a onetime purchase and installation cost.

\section{Projected Savings (Benefit) from Shortened Hospital Stays}

We based our estimate of benefit in terms of reduction in hospital stay, on the effect size of Abstract Romanticism paintings on mood uplift from research by Mozayeni and her colleagues (Amirmostofian \& Mozayeni, 2016; Mozayeni and Amirmostofian, 2016; and Mozayeni, et al., 2017). We ran a Repeated Measures Multivariate Analysis of Variance on the raw data from Amirmostofian and Mozayeni (2016). The dependent measure was the participants' mood after viewing paintings. Participants viewed painting at three different galleries including the Khavarani's Abstract Romanticism gallery. Thus, gallery was the within-subjects independent variable. The results showed a significant gallery effect $(F(2,249)=810.55$, $p=0.000$ ). The effect size (partial eta squared) was 0.867 . Essentially, $87 \%$ of the variance could be attributed to an increase in mood after viewing the Abstract Romanticism paintings. According to Cohen $(1977,1992)$, this is considered a large effect size.

We divided the effect rate by 1000 , based on the idea that the savings in hospital stay reduction will occur 1 in 1000 cases. Thus, the benefit factor is 0.000867 . We then multiplied this by the number of hospitalization days reported in the Hospital Statistics by State report from the American Hospital Directory for 2018. Reduction in cost was projected by multiplying the reduction in days by an estimate of per day cost of hospitalization. We used a conservative average estimate of $\$ 2,000$ per day, which was approximately $87 \%$ of the reported rate for Nonprofit Hospitals of $\$ 2,289 /$ per day. Table 1 shows the beds and total yearly hospital days per entities in our study. 
TABLE 1

BEDS AND DAYS DATA: NINE ENTITIES

\begin{tabular}{|c|c|c|}
\hline Entity & \#Beds & Hospital Days \\
\hline Mayo Clinic & 2033 & 454,344 \\
\hline Johns Hopkins & 1652 & 489,330 \\
\hline Mass General (MG) & 1052 & 320,673 \\
\hline CA & 73,898 & $14,206,798$ \\
\hline TX & 58,878 & $12,100,178$ \\
\hline NY & 56,469 & $11,686,524$ \\
\hline VT & 828 & 189,096 \\
\hline Alaska & 1,231 & 240,048 \\
\hline WY & 1,240 & 115,548 \\
\hline
\end{tabular}

Source: American Hospital Data (MCR) Report for 2018

\section{The Social Discount Rate}

For the Social Discount Rate, we used 4\%. This reflected the Fed's Inflation Target Rate of 2\%, plus the real rate of interest, as the nominal rate to account for inflation. We decided against the BLS's inflation rate of $5.67 \%$ because it seemed implausible, given that the cost of a one-day hospital stay of $\$ 2,000$ in 2019 would escalate to $\$ 113,933$ in the tenth year.

\section{RESULTS}

\section{Analysis by Hospital}

We used Excel to conduct the Cost-Benefit Analysis for all our cases, including the three top-ranking hospitals in the U. S., which are also teaching hospitals, namely Mayo Clinic, Johns Hopkins and Mass General. The initial benefit alone for all three surpassed their costs. In the first year, the benefits for Mayo Clinic is $\$ 790,558$, with a cost of $\$ 304,950$. For Johns Hopkins the first-year benefit was $\$ 851,434$ with a cost of $\$ 247,800$. For Mass General, the initial benefit was $\$ 557,971$, with a cost of $\$ 157,800$. We report their respective ratios in Table 3. All initial benefits are discounted in Excel. Over 10 years, their Present Value of Net Benefit (PVNB) was \$6,815,747, \$4,791,268 and \$7,423,091, respectively. These projections included the Salvage Value of the paintings (their initial values, less their installation costs, unadjusted for inflation or appreciation after 10 years). See Table 2. 
TABLE 2

DATA FOR NPVB CALCULATIONS, BENEFIT, AND COST COMPARISONS $\left(\mathrm{B}_{1} / \mathrm{C}\right) *$

\begin{tabular}{|c|c|c|c|c|c|c|}
\hline Entity & $\begin{array}{c}\text { Pieces } \\
\text { (\#Beds/2) } \\
(2) \\
\end{array}$ & $\begin{array}{l}\text { Cost } \\
\text { (C) } \\
\text { (3) }\end{array}$ & Days & $\begin{array}{c}\text { Initial Benefit } \\
\text { before } \\
\text { discounting } \\
\left(B_{1}\right) \\
(5) \\
\end{array}$ & \$ Salvage** & \$ NPVB \\
\hline Mayo & 1,016 & 304,950 & 454,344 & 790,558 & 254,150 & $6,617,819$ \\
\hline $\mathrm{JH}$ & 826 & 247,800 & 489,330 & 851,434 & 206,500 & $7,140,828$ \\
\hline MG & 526 & 157,800 & 320,673 & 557,971 & 131,500 & $4,680,370$ \\
\hline $\mathrm{CA}$ & 36,948 & $11,084,400$ & $14,206,798$ & $19,286,856$ & $9,737,000$ & $161,343,625$ \\
\hline $\mathrm{Tx}$ & 29,439 & $8,831,700$ & $12,100,178$ & $21,054,310$ & $7,359,750$ & $176,128,137$ \\
\hline NY & 28,234 & $8,470,350$ & $11,686,524$ & $20,334,552$ & $7,058,500$ & $170,116,839$ \\
\hline VT & 414 & 124,200 & 189,096 & 329,027 & 103,500 & $2,754,751$ \\
\hline $\begin{array}{c}\text { AK } \\
\text { Alaska }\end{array}$ & 615 & 184,500 & 240,048 & 417,683 & 153,750 & $3,492,545$ \\
\hline WY & 620 & 186,000 & 115,548 & 329,027 & 155,000 & $3,259,270$ \\
\hline
\end{tabular}

* $\mathrm{B}_{1}$ denotes the initial benefit

**Salvage Value/piece=Initial installed price (\$300)-installation cost of $\$ 50$

\section{Analysis by State}

Next, to illustrate the potential for savings as a result of installing uplifting artwork in patients' rooms, we considered the top three states with the largest number of hospital beds and the three bottom states. The top three are California, Texas and New York. The bottom three are Vermont, Alaska and Wyoming. These states also represent variations in size and regions of the country.

As shown in Table 2, we found that California had a one-time cost of $\$ 11,084,440$, but the benefit in the first year alone was $\$ 19,286,856$. For Texas, the cost was $\$ 8,831,700$, which is far offset by a benefit of $\$ 21,054,310$. For New York, the cost was $\$ 8,470,350$ and the first-year benefits were $\$ 20,3324,552$.

We reported the ratios for Initial Benefit/Cost and the NPVB/Cost ratios in Table 3. Clearly, in all three states, the benefits in the first year alone far exceed the costs. When Net Benefits were projected over 10 years, the benefit for all years were obviously higher. 
TABLE 3

INITIAL BENEFIT/COST AND NPVB/COST RATIOS

\begin{tabular}{|c|c|c|}
\hline Entity & Initial Benefit/Cost & NPVB/COST \\
\hline Mayo Clinic & 2.5 & 21.70 \\
\hline Johns Hopkins & 3.43 & 28.82 \\
\hline Mass General & 3.5 & 29.66 \\
\hline CA & 1.74 & 14.55 \\
\hline TX & 2.38 & 19.94 \\
\hline NY & 2.40 & 20.08 \\
\hline VT & 2.67 & 22.18 \\
\hline AK (Alaska) & 2.26 & 18.93 \\
\hline WY & 1.08 & 17.52 \\
\hline
\end{tabular}

As we report in Table 3, the initial benefit to cost ratio for all entities are higher than one, ranging from a low ratio of 1.08 (for Wyoming) and a maximum value of 3.5 for Mass General Hospital. Based on these ratios alone, it is obvious that the Net Present Value of Benefits (NPVB) in all cases far exceeded the one-time cost of the paintings. Although, mathematically it was obvious that the NPVBs would be higher, we calculated them to report the complete analysis.

For the top three states with the most beds, the NPVB value for California is above \$161 million, for Texas over \$176 million, and for New York over \$170 million. For the smallest states, Vermont had a NPVB of nearly $\$ 3$ million, Alaska was nearly over $\$ 3.5$ million, and Wyoming was over $\$ 3.25$ million. For the three hospitals in our study, the estimate is near $\$ 7$ million for Mayo Clinic and over $\$ 7$ million for Johns Hopkins, and more than $\$ 4.5$ million for Mass General.

We also calculated the ratios of NPVB of all entities to their C, where $C$ denotes a onetime cost. In our data the highest value of 29.66 for that ratio is for Mass General and the lowest value of 14.55 for the state of California, as we have recorded (See Table 3.).

Below, we summarize our findings and underscore our key points and offer policy recommendations for a public-private scheme for reducing the cost of hospital stays in the U.S.

\section{CONCLUSION}

The results demonstrate the quantitative value of art and project that the installation of Abstract Romanticism paintings in hospital rooms can lead to reduced hospital stays and cost savings. These results are consistent with Kaplan's attention restoration theory. In a hospital, the environment can be stressful and fatiguing for patients. Their attention is hyper-focused on the medical reason for their stay in the hospital. This prolonged mental effort can be mentally exhausting. Abstract Romanticism paintings because they match the four characteristics required for restoration: fascination, shifting focus away from stress, extent, and compatibility with the patient's inclinations can lead to stress reduction.

In this study we used a Cost-Benefit Model to quantify the costs and benefits of using Abstract Romanticism paintings in patient rooms in three hospitals, and six states. The Cost-Benefit Model is commonly used by both the Federal Government and World Bank for various projects. This model involves multiple estimates and researchers need to select these prudently to avoid double counting and exaggerated valuations. We have considered these judiciously to avoid such consequences.

We carefully measured Benefits and their NPVs. To determine the benefits, we conducted a Repeated Measures MANOVA Test to determine the "effect size" of mood change (0.867), as the result of viewing Abstract Romanticism paintings. We took a highly conservative fraction of this effect size (0.00087). This highly conservative fraction is an attempt to eliminate any risk associated with the effectiveness of the project. Along with that low rate, we also applied a conservative constant value of $\$ 2,000$ per day for the cost of hospitalization which is below the average for non-profit hospitals for 2018 . 
Furthermore, we have selected a short time horizon to allow flexibility for entities to switch their artwork and used a fairly low social discount rate that is the sum of the Federal Reserve's Inflation Target Rate $(2 \%)$, plus the real rate of interest $(2 \%)$.

The cost of paintings in our calculations is based on an actual projection from a vendor who sells Abstract Romanticism painting reproductions, who provided a written estimate for bulk purchases of reproductions for nonprofit entities. We added $\$ 50$ for installation of each piece. We also used an extremely conservative Salvage Value for the paintings after ten years, keeping at their initial values. We have assumed NO appreciation for the artworks and no inflation premium. The Salvage Value figure also excluded the installation cost.

Our benefits do not include secondary benefits to the employees (hence hospitals) or caregivers and resulting productivity gains to employees and to patients as a result of shorter hospital stays. We know that these represent the spillover of using uplifting art works in hospitals. Yet, their quantifications can be nebulous. So, we have not included them in our estimates. These additional benefits, mostly in the form of added productivity, can add social benefits through the economy as a whole.

Our results illustrated that the potential net benefit of using Abstract Romanticism Paintings to create "healing spaces" exceeds their cost by several fold.

For clarity, we enumerate the key facts relating to our methodology and hence the viability of this project.

1. Our research is evidence-based--the first in this area of research.

2. We based our evaluation of benefits on data demonstrating the effectiveness of Abstract Romanticism paintings to improve mood and took $1 / 1000$ of that rate to minimize the risk of projects.

3. We determined the nominal value of benefits, with the conservative figure of $\$ 2,000$ per day, well below the rate reported for the three types of hospitals and for the states we consider.

4. We enumerated only direct benefits.

5. We carefully determined our discount rate, which is the sum of the real rate of interest $(2 \%)$, plus the annual Fed's Inflation target of $2 \%$, amounting to $4 \%$ for estimating the nominal values for 10 years. We did not use the Bureau of Labor Statistic (BLS) inflation rate of $5.76 \%$ for hospital stay days to calculate the nominal values of benefits for the timeframe, because we considered it implausible given the current rate of inflation in the U.S and the typical cost of one day in the hospital.

6. We take a highly conservative value for the Salvage price of the paintings. We do not account for their potential appreciation or their nominal values after ten years.

\section{Future Research}

Cost-Benefit Analysis uses empirical evidence to project the likelihood that an intervention will have impact. The next step would be to validate this analysis by installing Abstract Romanticism artwork and evaluating its effect on patients. Ideally, an experiment using a randomized design comparing patient environments with Abstract Romanticism artwork to those without can be conducted. Patient emotional reactions, stress levels, amount and type of pain killers consumed, and the length of patient stays can be measured as outcome variables.

Another recommendation would be to investigate the benefits of Abstract Romanticism artwork on the satisfaction, stress levels, and performance of staff members. Do staff members provide better patient care when working in an environment with uplifting artwork that lead to restoration?

Research examining the aesthetic qualities of artwork that lead to stress reduction is needed. By identifying the artistic qualities that lead to quicker healing, hospital administrators will be better able to identify artwork with greater benefits. Examining aesthetic appreciation of visual artworks, Hager, Hagemann, Danner and Schankin (2012) revealed six factors: cognitive stimulation, negative emotionality, viewer's expertise, self-reference, artistic quality, and positive attraction. Attention restoration theory focused on fascination, shifting focus, extent, and compatibility. Pelowski, et al. (2018) found that artistic presence was associated with correspondence between viewer's emotions and those of 
the artist. Fascination/cognitive stimulation seems like a promising place to start. This could be combined with affective reactions--both positive and negative. In addition, Abstract Romanticism artwork could be compared and contrasted with art depicting nature on these aesthetic factors.

\section{Policy Recommendations}

We propose a progressive, innovative, and financially feasible way to reduce the cost of healthcare in the U.S. With leadership, such projects can benefit all stakeholders, including taxpayers by reducing costs associated with hospital stays. Currently, Medicaid and Medicare pay for about $50 \%$ of the cost of one day in a hospital and that cost is projected to rise. The daily hospital cost constitutes the largest component of healthcare costs in the U.S. (and beyond). It is projected to continue on that trajectory at an astonishing rate of nearly $6 \%$ per year, well above the CPI. If mood uplifting paintings are installed in hospitals, our results project that these programs may save billions of dollars. In addition, private insurance companies and patients themselves will realize substantial financial savings. Hospitals, who also benefit from their improved image and increased labor productivity, could partner with other beneficiaries to share the cost of the art contracts. Based on the "Benefit Principle," insurance companies can be invited to contribute to the cost of the artworks. The salvage value of the investment alone pays back for the initial costs. Thus, these results offer an evidenced-based research approach to reducing costs associated with patient hospital stays. The underlying rationale is that the Abstract Romanticism paintings will reduce stress and improve mood. We suspect that these results may have implications for any type of organization interested in improving their work environment. Based on these projections, the installation of Abstract Romanticism artwork in office buildings may lead to improved worker mood and reduced stress levels.

\section{REFERENCES}

American Hospital Directory: Hospital Statistics by States. (n.d.). Retrieved from https://www.ahd.com/state_statistics.html.

Amirmostofian, P., \& Mozayeni, S. (2016). Art for New Consciousness, Art for A New Humanity: An Empirical Investigation of Aesthetic Effect of Kamran Khavarani’s Paintings. International Journal of Social Sciences, 5, 27-46.

Baharlooei, O., Alavi, M., \& Adelmehraban, M. (2017). Psychosocial factors predicting length of hospitalization in elderly individuals with diabetes in selected hospitals of Isfahan University of Medical Sciences, Isfahan, Iran, in 2015. ARYA Atherosclerosis, 13(3), 103-108.

Boime, A. (2008a). The Birth of Abstract Romanticism, Art for a New Humanity, Art for a New Consciousness, Rumi and the Paintings of Kamran Khavarani. San Francisco, CA: Sybil City Book Company. ISBN: 978-0-9816739-2-9, Collector's Edition.

Boime, A. (2008b, July 28). From the Desk of Albert Boime. Department of Art History, UCLA. Retrieved November 11, 2015, from http://albertboime.com/Letters.cfm

Cohen, J. (1977, 1992). Statistical power analysis for the behavioral sciences. Hillsdale, NJ: Lawrence Erlbaum.

Eisen, S. L., Ulrich, R. S., Shepley, M. M., Varni, J. W., \& Sherman, S. (2008). The stress-reducing effects of art in pediatric health care: Art preferences of healthy children and hospitalized children. Journal of Child Health Care, 12(3), 173-190. https://doiorg.libdatabase.newpaltz.edu/10.1177/1367493508092507

Hager, M., Hagemann, D., Danner, D., \& Schankin, A. (2012). Assessing aesthetic appreciation of visual artworks-The construction of the Art Reception Survey (ARS). Psychology of Aesthetics Creativity and the Arts, 9, 320-33. DOI: 10.1037/a0028776

Hathorn, K., \& Nanda, U. (2008). A Guide to Evidence-Based Art. Concord. CA: Center for Health Design, 1-24.

Hyman, D. N. (2010). Public Finance, A Contemporary Application of Theory and Policy, $11^{\text {th }}$ Ed. Mason, OH: South-Western--Cengage Learning. Ch. 6, pp 223-250. 
Kaplan, S. (1995). The restorative benefits of nature: Toward an integrative framework. Journal of Environmental Psychology, 15, 169-182.

Kawabata, H., \& Zeki, S. (2004). Neural Correlates of Beauty. Journal of Neurophysiology, 91, 16991705. doi: 10.1152/jn.00696.2003

Kragel, P. A., Reddan, M. C., LaBar, K. S., \& Wager, T. D. (2019). Emotion schemas are embedded in the human visual system. Science Advances, 5(7), eaaw4358. https://doiorg.libdatabase.newpaltz.edu/10.1126/sciadv.aaw4358.

Lankston, L., Cusack, P., Fremantle, C., \& Isles, C. (2010). Visual Art in Hospitals: Case Studies and Review of Evidence. Journal of Royal Society of Medicine, 103(12), 490-499.

Mavros M.N., Athanasiou S., Gkegkes I.D., Polyzos K.A., Peppas G., \& Falagas, M. E. (2011). Do Psychological Variables Affect Early Surgical Recovery? PLoS ONE, 6(5), e20306. doi:10.1371/journal.pone.0020306

Miles, M. F. R. (1994). Art in hospitals: Does it work? A survey of evaluation of arts projects in NHS. Journal of the Royal Society of Medicine, 87, 161-163.

Mozayeni, S., \& Amirmostofian, P. (2016). Comparison of Parametric and Nonparametric Modeling: Aesthetic Effect of Kamran Khavarani's Paintings. International Journal of Social Sciences, 5(1), 72-92.

Mozayeni, S., Heiner, K., \& Amirmostofian, P. (2017). A Pattern Analysis Application: Time Series Traces of the Effect of Kamran Khavarani's Paintings on Viewers' Mood. International Journal of Social Sciences, 6(2), 44-62.

Pelowski, M., Leder, H., Mitschke, V., Specker, E., Gerger, G., Tinio, P. P. L., ... Husslein-Arco, A. (2018). Capturing Aesthetic Experiences with Installation Art: An Empirical Assessment of Emotion, Evaluations, and Mobile Eye Tracking in O. Eliasson's "Baroque, Baroque!". Frontiers in Psychology, 9, 1255. https://doi-org.libdatabase.newpaltz.edu/10.3389/fpsyg.2018.01255

Pelowski, M., Specker, E., Gerger, G., Leder, H., \& Weingarden, L. S. (2018). Do you feel like I do? A study of spontaneous and deliberate emotion sharing and understanding between artists and perceivers of installation art. Psychology of Aesthetics, Creativity, and the Arts. Advance online publication. https://doi.org/10.1037/aca0000201

Sherman, S. A., Varni, J. W., Ulrich, R. S., \& Malcarne, V. L. (2005). Post-occupancy evaluation of healing gardens in a pediatric cancer center. Landscape \& Urban Planning, 73(2/3), 167-183. https://doi-org.libdatabase.newpaltz.edu/10.1016/j.landurbplan.2004.11.013

Smith, L. F., Smith, J. K., \& Tinio, P. P. L. (2017). Time spent viewing art and reading labels. Psychology of Aestetics, Creativity, and the Arts, 11, 77-85.

Sternberg, E. (2009). Healing Spaces: The Science of Place and Well-Being. Cambridge, MA: Belknap Press of Harvard University.

Tinio, P. P. L., \& Gartus, A. (2018). Characterizing the emotional response to art beyond pleasure: Correspondence between the emotional characteristics of artworks and viewers' emotional responses. Progress in Brain Research, 237, 319-342. https://doiorg.libdatabase.newpaltz.edu/10.1016/bs.pbr.2018.03.005

Ulrich, R. (1984). View Through a Window May Influence Recovery from Surgery. Science, 224, 420421, DOI: $10.1126 /$ science.6143402.

Ulrich, R. S. (2006). Evidence-based health-care architecture. Lancet, 368, 38-39. https://doiorg.libdatabase.newpaltz.edu/10.1016/S0140-6736(06)69921-2

Ulrich, R. S. (2013, January 13). Designing for Calm. New York Times, p.12. Retrieved from https://libdatabase.newpaltz.edu/login?url=https://search-ebscohostcom.libdatabase.newpaltz.edu/login.aspx?direct $=$ true $\& d b=0 i h \& A N=84761388 \&$ site $=$ ehost-live

Ulrich, R. S., Bogren, L., Gardiner, S. K., \& Lundin, S. (2018). Psychiatric ward design can reduce aggressive behavior. Journal of Environmental Psychology, 57, 53-66. https://doiorg.libdatabase.newpaltz.edu/10.1016/j.jenvp.2018.05.002

Wisely, J. (2013). The impact of psychological distress on the healing of burns. Wounds UK, 9(3), 14-17. 